\title{
MORTE, CULPA E MEDO \\ A ANGÚSTIA COLETIVA NO PRINCÍPIO DA MODERNIDADE
}

Alexandre Frasato Bastos ${ }^{55}$

"Tudo vai mal...".

Eustache Dechamps

Resumo: O presente artigo é parte do primeiro capítulo de minha monografia de bacharelado intitulada "Tempos de Angústia - Erasmo e Lutero no Início da Modernidade". O objetivo de minha pesquisa é relacionar o Humanismo Cristão e a Reforma Religiosa, partindo do debate historiográfico que reconhece serem ambos respostas às necessidades de seu tempo, marcado por uma forte angústia coletiva experimentada no período de trańsição do Medievo para a Modernidade, mas também pela atitude intelectual de conhecimento e ação no mundo. É este contexto que abordamos neste artigo, enfatizando os elementos que podem nos ajudar a compreender essa angústia coletiva.

Palavras chave: Humanismo, Reforma, Transição do Medievo para a Modernidade.

\section{1 - "MEMENTO MORI".}

Guerras, pestes, reis loucos, fome, morte. O Juízo Final nunca antes pareceu tão iminente. Os inimigos da cristandade se multiplicam, em diversas formas: turcos, idólatras, judeus, heréticos, bruxas, entre outros. Mas o pior inimigo, o verdadeiro culpado pelas adversidades do período não estava tão longe. De fato, era o que estava mais próximo. O maior medo, que cada vez crescia mais, era o medo de si mesmo. Afinal, foram os pecados da humanidade que atraíram estes males para o mundo, e a preocupação com a salvação pessoal, não mais nesta vida, mas sim na próxima, passa a ser o foco principal das atenções.

Na conturbada transição do Medievo para a Modernidade é notável uma forte angústia coletiva, fomentada pelas preocupações mencionadas acima, que são o tema deste artigo. Pretenderemos demonstrar que este sentimento de angústia, essa preocupação com a salvação pessoal levou a uma nova configuração da mentalidade da sociedade européia neste período, que não mais se contentou com os dogmas católicos, demandando por novas saídas, novas explicações para seus anseios. A primeira questão que pretenderemos responder é, portanto, quais foram as características deste período, notadamente o intervalo entre os séculos XIV a XVI, que ocasionaram esta transformação de mentalidade? 
Como afirmamos acima, diversos acontecimentos trágicos ocorridos na Europa num relativamente curto período de tempo levaram muitos a crer na proximidade do Juízo Final. A Guerra dos Cem Anos (1337-1453), travada entre duas das maiores potências da época, França e Inglaterra; a Guerra das Duas Rosas, na Inglaterra, somente dois anos depois da derrota perante a França; a crescente ameaça turca nos muros de Constantinopla; a forte crise religiosa com o Cisma do Ocidente e, talvez acima de todos estes fatores, a Peste Negra, levaram muitos contemporâneos a uma visão extremamente pessimista do mundo. A morte parecia efetivamente próxima e a convivência com ela era freqüente. Sua inevitabilidade era evidente, podendo ocorrer a qualquer momento, e este momento parecia estar cada vez mais próximo.

Contudo, não era só a morte que estava próxima. O contato com o "outro mundo", com o "além", também era vivido de forma mais intensa. As crenças muito comuns em fantasmas e aparições foram incorporadas francamente pelo Cristianismo, sobretudo no tocante aos pregadores, que se utilizavam destas histórias como exemplos edificantes (DELUMEAU, 2003). É notável esta confluência de crenças em um soneto composto por Amadis Jamyns, intitulado "Dos espíritos dos Mortos", citado por Delumeau:

\section{As Sombras, os Espíritos, os ídolos horriveis \\ Dos Mortos carregados de ofensa erram durante a noite: \\ E para mostrar a pena e o mal que os afugenta \\ Fazem gemer o silêncio em longas vozes confusas, \\ Porque são privados das delícias felizes \\ Que a alma após a morte no Paraíso persegue, \\ Como banidos do dia nas trevas fazem rumor, \\ Implorando socorro para suas penas vergonhosas.}

Neste trecho nota-se que a crença em fantasmas - não só como evidência de uma vida pósmorte, mas como espectros que verdadeiramente vagam durante a noite pelo mundo dos vivos contrasta e se une à concepção da fé católica no Purgatório, isto é, que as almas dos homens devem penar pelos seus pecados para alcançar a glória no Paraíso. De fato, não só na literatura, mas nas diversas artes aumentaram as representações tanto do Juízo Final, como também, e principalmente, da própria Morte, apresentada como a Rainha da Terra, cujo poder ninguém, por mais abastado, culto ou puro que fosse poderia resistir, como na conhecida fórmula latina "mors omnia aequat": a morte a todos iguala. Portanto, esta aquiescência da proximidade, esta resignação frente à Morte nos leva a crer que não era ela em si que os homens e mulheres temiam, mas sim o que seria deles após a sua visita.

E esta foi, de fato, uma época de grandes contrastes, como Huizinga nos apresenta. As emoções e as experiências do cotidiano são percebidas de forma muito mais intensa. 0 escuro, as trevas, 
eram muito mais temidos, devido às criaturas que nela supostamente habitavam. O frio causava mais impacto a uma população cujas moradias não eram cômodas e cujas roupas eram precárias. Não se conheciam os motivos das doenças, explicadas na maior parte das vezes como pragas de bruxas ou punições de Deus. Todos estes fatores levavam a uma maior ritualização da vida cotidiana: acontecimentos simples como viagens e visitas eram constituídos de tantas fórmulas e ritos quanto os casamentos e nascimentos (HUIZINGA, 1985). Neste sentido, podemos perceber um retorno a um cristianismo primitivo, para o qual, como veremos mais adiante, o clero não estava preparado para atender. No momento, o que queremos sublinhar é a maior susceptibilidade dos sentidos e do imaginário, que foram aproveitados pela Igreja através de seus pregadores para implantar o temor na alma de seus fiéis.

À angústia inicialmente referida soma-se também uma forte melancolia, um pessimismo com relação a todos os aspectos da sociedade. No cerne disso tudo surge a certeza nutrida pelo cristianismo de que o homem é um grande pecador pois, nas palavras de Delumeau, "a infelicidade existe porque existe o mal. Um e outro se explicam pelo pecado, do qual a melancolia é filha" (DELUMEAU, 2003).

Portanto, frente a tudo isto, a explicação corrente, propagada pela Igreja Católica - principal refúgio para os males e temores da sociedade - é a de que todos estes acontecimentos trágicos, estes sentimentos de angústia e melancolia, seriam a punição divina pelos pecados cometidos pela humanidade (DELUMEAU, 1989). E é esta preocupação com o pecado, com os escrúpulos, e principalmente com a salvação pessoal, que levou quase toda uma sociedade a temer a si mesma como Jean Delumeau defende na Introdução de sua obra "O Pecado e o Medo". Fortalece-se cada vez mais o discurso eclesiástico de que a natureza humana é propensa a todos os males e as recorrentes perseguições aos hereges, ocorridas desde o Medievo, propagam esta visão, somada à idéia também cada vez mais freqüente de que a cada um cabe sua própria salvação.

Neste contexto de medos e angústias encontramos, de acordo com Delumeau, a transição das "religiões da tranqüilidade", características do Oriente, como o Hinduísmo e o Budismo, para a "religião da ansiedade", proveniente do cristianismo ocidental. E esta ansiedade é proveniente principalmente da idéia do pecado, o ato humano que nos separa de Deus, que nos afasta da salvação após a morte. Ao colocar o pecado como tema central de sua teologia, o Cristianismo traz também a culpa como uma grande preocupação dos homens.

Na Antiguidade, notadamente para Aristóteles, a culpa é um erro, gerado por alguma inaptidão humana. Mais do que isso, os erros dos homens e mulheres eram premeditados pelos deuses, que intervinham em seus atos, fato recorrente na Mitologia greco-romana. Contudo, no Cristianismo, invertem-se as posições, pois os erros humanos que incorrem em pecado são desobediências diretas às ordens divinas. Sofrendo a influência do judaísmo, o Cristianismo "fez do pecado uma oposição da vontade do homem à vontade de um Deus pessoal", não somente através de ações diretas, mas também por pensamentos e sentimentos. Surgem no latim os termos peccator e peccatrix, referindo-se às pessoas que incorriam no pecado, termos esses que não existiam no latim clássico (DELUMEAU, 2003). 
Ao longo da Idade Média, a discussão sobre o pecado se ampliou, bem como o impacto deste na mentalidade dos fiéis. O IV Concílio de Latrão, em 1215, impõe a confissão anual aos cristãos, fazendo surgir diversos manuais de confissão e diversas sumas de confessores, alimentando ainda mais a literatura e o debate sobre o pecado. Nem mesmo os Pecados Capitais permanecem os mesmos, variando inclusive em número, até serem estabelecidos os sete pecados que conhecemos hoje. Estes manuais se detêm a listar todos os pecados possíveis, desde o beijo impuro até posições inconvenientes no ato sexual, no intuito de instruir os fiéis sobre o que relatar no ato da confissão. Cresce também o debate, refletido no imaginário dos fiéis, sobre a natureza divina: afinal, Deus é bom ou Deus é justo?

O que nos importa no momento nesta questão do recrudescimento da discussão sobre o pecado e a obrigação da confissão é a força que exerce sobre a mentalidade dos cristãos da época, e o impulso que estes fatos dão ao advento da individualidade, pois dificilmente se negará que, ao se defrontar com a obrigatoriedade da confissão e com as enormes listas das afrontas que poderiam ser cometidas, o fiel se propusesse a um auto-exame, uma autocrítica levando, certamente, a uma maior consciência de si mesmo e de suas ações. Afinal, também a ignorância passa a ser um pecado, portanto não se saber pecando não é mais uma escusa para seu erro. O Cristianismo, através dos sermões e dos pregadores, passou a propagar com mais ênfase a idéia do hómem deturpado pelo Pecado Original, já maculado desde o nascimento. Portanto, cabe a ele seguir o seu destino, buscando a salvação sem, obviamente, sair dos braços da própria Igreja, pois sobretudo, não havia salvação fora dela.

\section{2 - SACRALIZAÇÃO DO LAICO, LAICIZAÇÃO DO SAGRADO.}

Muitos fiéis buscavam conforto em lugares diversos. Houve na época uma difusão do culto à Virgem, numa busca por refúgio dos males desta vida e do inferno. Delumeau atesta certo retorno ao politeísmo através do culto aos diversos santos. Este fato explica também o sucesso inicial da venda das indulgências, como garantia para um bem viver no além. Contudo, o fiel passa a sentir-se cada vez mais só e menos protegido pela Igreja. Num momento em que os cristãos mais precisam de sua Igreja esta se mostra cada vez mais distante. O retorno dos fiéis ao cristianismo primitivo fez com que a liturgia tradicional da Igreja Católica - a missa em latim, os sacramentos - não mais fosse suficiente para eles, parecendo-Ihes estranha e incapaz de apaziguar suas angústias. Há uma superabundância de padres, enquanto faltam pastores, o que aumenta esse sentimento de abandono: a Igreja não mais conseguia comunicar-se efetivamente com seu rebanho. O sacerdócio, portanto, passava por uma depreciação.

Na Idade Média a existência de uma sociedade rural altamente hierarquizada e celular permitiu uma sociedade cristã dominada pela hierarquia eclesiástica, de acordo com Delumeau. Contudo, muitos fatores levaram os fiéis a terem dificuldades para distinguir o sacro do profano e o padre do leigo. Entre estes fatores podemos destacar a ascensão de um novo estrato social, a burguesia, contribuindo para a formação de uma civilização cada vez mais urbana e laica, com o aparecimento 
do luxo e a crescente afirmação de sentimentos nacionais. Também o exacerbado materialismo de muitos membros do clero levou a uma depreciação deste. E, de fato, há alguns séculos que os limites políticos dos Imperadores e dos Papas vinham sendo constantemente postos à prova em debates iniciados pela discussão da própria natureza humana.

Estas discussões alcançavam os fiéis, como já mencionado acima. Ainda que a grande maioria do povo não participasse diretamente dos debates, seus efeitos eram evidentemente sentidos. Um exemplo notável disto é o citado por Huizinga (HUIZINGA, 1985), ao abordar o Cisma do Ocidente. Afinal, em um relativamente curto período de tempo, surgiram três pretendentes ao trono eclesiástico. Mesmo que não tenha sido motivado por razões dogmáticas, mas sim políticas, o Cisma arrebanhou fiéis para ambas as causas, a de Roma e a de Avinhão, sendo que os dois lados encaravam o entrave como uma espécie de guerra santa. De fato, os partidários de cada lado expunham sua fidelidade através de diversos sinais, como insígnias e cores de roupas diferenciadas.

Contudo, o que nos parece mais significativo é que, neste momento onde, reafirmamos, as multidões mais careciam do alento da Igreja, esta se afastava. Muitas vezes os fiéis são impedidos de assistir missas em suas cidades, pois, por questões políticas em algumas regiões as missas chegaram a ficar interditadas por meses, privando os fiéis de seus sacramentos, afastando-os ainda mais da salvação e conforto tão procurados. De fato, em uma civilização por demais religiosa, torna-se difícil uma delimitação precisa entre Igreja e Estado. O terreno laico invadia cada vez mais atribuições outrora exclusivas da Igreja, socorrendo pobres, construindo hospitais e diversas outras obras de caridade. Então, neste mundo de limites tênues, Delumeau nos lança o questionamento: "já que se viam leigos melhores que homens da Igreja, não seria possível concluir que um leigo de vida santa é um padre mais autêntico que um eclesiástico?" (DELUMEAU, 1989).

Com esse sentimento de abandono, essa angústia fortalecida por diversos acontecimentos trágicos, novas respostas são exigidas pelos fiéis. $\mathrm{E}$, de fato, o terreno para estas respostas começa a ser preparado por um movimento intelectual denominado Renascença.

\section{3- RESPOSTAS À ANGÚSTIA}

De fato, muitos renascentistas fomentavam a imagem da Idade Média como um período de trevas. E esta triste realidade vivida suscitava uma nostalgia coletiva, por tempos melhores que aqueles em que viviam, mas também melhores ao que os precederam imediatamente. Encaramos, portanto, o Renascimento como um preparador de terreno para novas respostas, pois surge como um antídoto para a angústia: não o consideramos de fato otimista, mas sim o contrário: as pessoas eram certamente pessimistas com relação aos tempos em que viviam, mas ainda assim eram esperançosos de uma realidade melhor.

Contudo, a necessidade dos fiéis de se apoiarem em uma autoridade infalível em tempos de dúvida quanto aos padres e aos dogmas católicos, fez surgir a demanda por outras respostas aos seus 
questionamentos, e o primeiro desses retornos surgiu com o Humanismo.

O Humanismo surge inicialmente, neste contexto, com um grupo de indivíduos que buscava atualizar e dinamizar a forma como eram ministrados os estudos nas Universidades medievais, que se voltavam somente a três carreiras, o direito, a medicina e a teologia. Os humanistas se dedicaram aos studia humanitatis, os estudos humanísticos, que incluíam a poesia, a filosofia, a história, a matemática e a eloqüência, sendo esta última uma fusão entre retórica e filosofia. Contudo, com o crescimento e a expansão das idéias humanistas, estas já não se restringiam mais a somente uma renovação nos estudos, ampliando suas preocupações a toda a sociedade, criticando a cultura tradicional e buscando parâmetros centrados no indivíduo e em suas capacidades. O Humanismo expandiu-se da sua origem, na Itália, para as principais cidades européias. De acordo com Skinner, esta expansão se deu através de estudiosos que vão do Norte da Europa - especialmente da França, Inglaterra e Alemanha - para as Universidades da Itália, buscando uma formação melhor e mais conceituada, voltando depois aos seus países para lecionar em outras Universidades, induzindo o "desencadeamento de uma revolução intelectual que acabaria levando à derrubada da escolástica" (SKINNER, 1996, p.217).

Com essa expansão, surgiram diversas linhas e tendências de estudos diferenciadas dentro do próprio Humanismo. A vertente que nos interessa mais para esta pesquisa é o Humanismo Cristão, centrada principalmente no Norte da Europa, agregando homens que buscavam uma religião renovada, tendo como expoente Erasmo de Rotterdam, autor de vários ensaios e estudos sobre teologia, mais conhecido pela obra satírica "O Elogio da Loucura", na qual critica diversos setores da sociedade, principalmente os eclesiásticos, por sua ganância e imoralidade. Esta vertente do humanismo tinha como principal objeto de estudo a própria Bíblia, empenhando-se em aplicar os métodos filológicos em seu estudo, adotando necessariamente uma nova abordagem exegética, de acordo com Skinner (SKINNER, 1996).

Contudo, o movimento humanista não se resume a esta renovação nos métodos de estudo, tendo impacto em diversos setores da sociedade. Le Goff, em seu livro Os Intelectuais na Idade Média apresenta os humanistas como uma aristocracia, um grupo de intelectuais que ensina para um grupo de elite, no Collège des Lecteurs Royaux (futuramente, Collège de France). Há uma diferenciação não somente intelectual com relação aos pensadores medievais, mas também social. Os pensadores humanistas freqüentam as cortes, protegidos pela nobreza, aconselhando príncipes e nobres. É, portanto, necessário sublinhar que o humanismo não se restringe somente ao meio acadêmico, expandindo seus estudos e sua influência para conceitos morais e éticos, com preocupações sociais e religiosas, fora do âmbito das Universidades. Longe de ser somente um novo método de estudos e de análise de textos, os ideais humanistas estiveram presentes em diversos aspectos da vida desses indivíduos, influenciando a sociedade e o contexto em que viviam.

A principal contribuição humanista (principalmente do humanismo cristão), no tocante às angústias sentidas no período se dá através das diversas publicações religiosas editadas por aqueles eruditos, impulsionados principalmente pelo surgimento da imprensa. A necessidade já afirmada dos 
fiéis de se apoiarem em uma autoridade infalivel, quando em dúvida com relação aos homens da Igreja, levava-os a buscar conforto na Bíblia e em demais publicações religiosas, que representavam a grande maioria nas tipografias da época ${ }^{56}$. Assim, mesmo antes da Reforma Luterana, a Bíblia já havia sido traduzida e publicada em diversos idiomas, e humanistas como Erasmo empenhavam-se não somente em traduzi-la, mas ainda corrigir erros que haviam se consolidado através dos anos, como na edição do Novo Testamento de 1516, traduzida e publicada por ele. Isto permite o crescimento do individualismo do fiel, que não mais necessitava do padre para refletir sobre a Bíblia, pois esta se tornava cada vez mais acessível ao público letrado. Assim, o padre era cada vez menos necessário, pois a obra impressa permitia uma meditação pessoal (DELUMEAU, 1989).

Podemos entender o Humanismo, neste sentido, como um precursor e preparador da Reforma. Contudo, mostra-se insuficiente, pois apesar de se mostrar muito mais religioso do que a historiografia pretendeu por muito tempo ${ }^{57}$, não oferece conforto e esclarecimento das dúvidas dos cristãos quanto às suas angústias religiosas. Estas somente serão apaziguadas com o advento dos diversos movimentos reformistas subseqüentes, que ofereceram a base religiosa que não foi central no Humanismo, mas que ainda era necessária aos homens e mulheres da época. A Reforma Luterana ofereceu, então, uma aproximação maior do fiel com a religião, simplificando em muitos aspectos a liturgia tradicional. Contudo, sabe-se que os próprios humanistas relutaram em aderir à Reforma, o que geralmente não aconteceu ${ }^{58}$, na maioria dos casos. Isto se dá por diversos fatores como, por exemplo, a reprovação da violência e da ruptura com a Igreja, tópico este que abordei em minha monografia quando tratei das relações entre Erasmo de Rotterdam e Martinho Lutero, os autores que escolhi para compreender as relações entre ambos os movimentos.

\section{REFERÊNCIAS}

DELUMEAU; Jean. Nascimento e Afirmação da Reforma. São Paulo-SP: Pioneira, 1989

DELUMEAU, Jean. O pecado e o medo - a culpabilização no ocidente (séculos 13-18). Bauru: EDUSC, 2003. 2 v. HUIZINGA, Johan. O declínio da Idade Média. Lisboa: Ulisséia, 1985.

KRISTELLER, P. O. El Pensamento Renacentista y sus fuentes. México : Fondo de Cultura Econômica, 1982 SKINNER, Quentin. As fundações do Pensamento Político Moderno. Companhia das Letras, São Paulo, SP, 1996.

56 De acordo com Delumeau, esse número chegaria a $75 \%$ das publicações.

57 Como podemos aferir a partir da leitura de KRISTELLER, P. O. EI Pensamento Renacentista y sus fuentes. México: Fondo de Cultura Econômica, 1982.

58 Com exceção da própria Alemanha, onde podemos citar o caso do eminente humanista Melanchton, companheiro de Lutero. 